\title{
Obtaining hepatocytes by transdifferentiation of multipotent mesenchymal stromal cells by genetic engineering
}

\author{
Oleg Makeyev ${ }^{1,2}$, Arteom Korotkov ${ }^{1,2}$, Svetlana Kostyukova ${ }^{1,2}$, Evgeny Shuman ${ }^{1,2,3}$, and \\ Mariya Desyatova ${ }^{1}$ \\ ${ }^{1}$ Ural State Medical University, 620028, Repin Str., 3, Ekaterinburg, Russian Federation \\ ${ }^{2}$ Institute of Medical Cell Technology, 620026, Ekaterinburg, Russian Federation \\ ${ }^{3}$ Ural Federal University, 620002, Mira Str., 19, Ekaterinburg, Russian Federation
}

\begin{abstract}
Therapy of liver failure is a common and insufficiently resolved problem. One of the options for its solution it is a liver transplantation. However, this method has a number of drawbacks, which include a limited number of donors and transplant rejection. The use of autologous hepatocytes would allow significant progress to solve the problem under discussion. The work considers a method that allowed obtaining autologous hepatocytes by transdifferentiation of multipotent mesenchymal stromal cells using genetic engineering methods.
\end{abstract}

\section{Introduction}

Lack of liver function is a pathology, for the treatment of which organ transplantation remains a practically non-alternative method. Despite the obvious successes of transplantology, the effectiveness of liver transplantation remains low [1,2].

In this regard, the development of new methods for correcting liver failure is aimed at reducing the number of patients who are shown organ transplantation. Thus, the discovery of liver regeneration factors made it possible to use their recombinant analogues for the treatment of liver failure. However, the short lifetime of these peptides makes it necessary for their continuous long-term administration and a wide spectrum of action in relation to other cells and tissues limit the possibilities of their clinical use. [3, 4].

Successful attempts to use gene technologies for introducing genes encoding these proteins into liver tissue cells are known. Meanwhile, the efficiency and selectivity of in vivo transfection is extremely small. The best effect is achieved with the use of virus-based vectors, however, the possibility of recombination of the viral base and / or their integration into the genome significantly limits their clinical use [5].

On the other hand, there are known attempts to introduce mesenchymal stromal cells (MMSC), in some cases accompanied by some clinical effect. Moreover, recent studies have shown that MMSCs are able to transdifferentiate into tissue cells of various germ layers [6, 7], including hepatocytes. 
Although in a number of studies, the authors failed to obtain significant clinical effects. $[8,9]$, it was shown that the regenerative potential of mesenchymal multipotent stromal cells derived from adipose tissue (aMMSC) in relation to liver tissue is higher than that extracted from bone marrow [10], as well as their proliferative potential and transdifferentiation ability. Isolation of aMMSC is less traumatic, and the content per gram of tissue is 40 times higher [11].

However, several independent research groups have shown that only a very small fraction of the MMSCs administered differentiate into hepatocytes. $(<0.01 \%)$ [12-15], and the mechanism of stimulating liver regeneration and the mechanism of homing of MMSC into the affected liver remains largely unclear.

An alternative is to obtain hepatocytes from MMSC in vitro. In this case, when using autologous MMSCs, it becomes possible to obtain hepatocytes with a high therapeutic value, and the process itself is well controlled and makes it possible to use non-viral (plasmid) based vectors as vectors.

Based on the foregoing, the aim of this study was to obtain autologous heptocytes for the development of further cell therapy of liver failure.

The objectives of this study were:

1) to develop a technology for the transfection of multipotent mesenchymal stromal cells (MMSC) with plasmid vectors with the HGF gene (hepatocyte growth factor) to obtain transfected MMSC (tMMSC);

2) to study the expression of hepatocyte marker genes in tMMSC and their synthesis of urea and alpha-fetoprotein to confirm their hepatocytic differentiation.

\section{Materials and methods}

Multipotent mesenchymal stromal cells were obtained from lipoaspirate from six clinically healthy women aged 34-41 years with their informed consent.

We used pBABE-puro (Addgene plasmid 176) as the basis of the vector. The synthesis of DNA encoding HGF was carried out by reverse transcription using the RTS kit (Promega). PCR primers are designed using data and programs located on the NCBI website.

Cells were removed from vials using $0.25 \%$ trypsin solution (Sigma Aldrich). Filmed cells were placed in $24 \mathrm{x}$ well plates. Upon reaching $70 \%$ confluence, the control group of cells was continued to incubate in DMEM supplemented with $10 \% \mathrm{FBS}, 10 \mathrm{ng} / \mathrm{ml}$ FGF, 100 units / $\mathrm{ml}$ penicillin and 100 units / $\mathrm{ml}$ streptomycin (Sigma), the experimental group of cells was transfected with pBABE-puro HGF (Addgene ) using the Lipofectamine TM 2000 kit (Invitrogen) according to the manufacturer's protocol and then cultured in DMEM supplemented with $10 \%$ FBS, $10 \mathrm{ng} / \mathrm{ml} \mathrm{FGF,} 100 \mathrm{u} / \mathrm{ml}$ penicillin and $100 \mathrm{u} / \mathrm{ml}$ streptomycin (Sigma Aldrich). A change of medium was performed every 3 days. The exchange medium was collected and stored at $-20^{\circ} \mathrm{C}$ for subsequent determination of alpha-fetoprotein and urea.

PAS staining was performed according to standard procedures. [16]. 21 days after transfection, the cells were removed with trypsin and passaged into 6 well plates at the rate of $1 * 104$ cells / cm. After a day, the cells were washed with PBS solution (Sigma) and fixed with formalin / methanol for 1 minute, after which the cells were treated with iodic acid solution for 1 minute, and then stained with Schiff's reagent (Sigma) for 1-5 minutes.

RT PCR was performed according to the method described by Bustin [17]. Matrix RNA was isolated using the GenElute TM Direct mRNA Miniprep Kit (Sigma) according to the manufacturer's protocol. 
DNA was synthesized in a mixture containing $200 \mu \mathrm{g}$ of RNA using the SYBR ${ }^{\circ}$ Green Quantitative RT-PCR Kit (Sigma).

DNA synthesis was performed in a mixture containing $200 \mu \mathrm{g}$ of RNA using the SYBR ${ }^{\circledR}$ Green Quantitative RT-PCR Kit (Sigma Aldrich).

The primers used in the synthesis of DNA are shown in table 1. The final reaction mixture contained $0.8 \mu \mathrm{l}$ of each primer and $2.5 \mu \mathrm{l}$ of nuclear DNA. After denaturation for 5 minutes at $95^{\circ} \mathrm{C}$, amplification was performed over 40 cycles.

Data normalization was performed online at www.genevestigator.com.

Table 1. Primers used in DNA synthesis

\begin{tabular}{|c|c|c|}
\hline Primer Name & Sequenc & $\begin{array}{c}\text { Annealing } \\
\text { temperature, }{ }^{\circ} \mathrm{C}\end{array}$ \\
\hline Beta Actin Direct & 5-GGGCATGGGTCAGAAGGATT-3 & 56 \\
\hline Beta actin reverse & 5-GAGGCGTACAGGGATAGCAC-3 & 56 \\
\hline Alpha fetoprotein, direct & 5-TGCAGCCAAAGTGAAGAGGGAAGA-3 & 58 \\
\hline Alpha fetoprotein, reverse & 5-CATAGCGAGCAGCCCAAAGAAGAA-3 & 58 \\
\hline Cytokeratin 18, прямой & 5-ATGGGAGGCATCCAGAACGAGAA-3 & 58 \\
\hline Cytokeratin 18, reverse & 5-GGGCATTGTCCACAGTATTTGCGA-3 & 58 \\
\hline Albumen, direct & 5-TGCTTGAATGTGCTGATGACAGGG-3 & 58 \\
\hline Albumen, reverse & 5-AAGGCAAGTCAGCAGGCATCTCATC-3 & 58 \\
\hline $\begin{array}{l}\text { Tryptophan 2,3-Dioxigenase, } \\
\text { direct }\end{array}$ & 5-AGTCAAACC TCCGTGCTT-3 & 58 \\
\hline $\begin{array}{l}\text { Tryptophan 2,3-Dioxigenase, } \\
\text { reverse }\end{array}$ & 5-TCGGTGCATCCGAGAAACA-3 & 58 \\
\hline $\begin{array}{l}\text { Tyrosinaminotransferase, } \\
\text { direct }\end{array}$ & 5-CTCAATTCTGGACGTGCATG-3 & 52 \\
\hline $\begin{array}{l}\text { Tyrosinaminotransferase, } \\
\text { reverse }\end{array}$ & 5-GCTGGTTGGAGAAGATGGCA-3 & 52 \\
\hline $\begin{array}{l}\text { Alpha 1 Antitrypsin } \\
\text { (Glycoprotein), direct }\end{array}$ & 5-TCGCTACAGCCTTTGCAATG-3 & 55 \\
\hline $\begin{array}{l}\text { Alpha } 1 \text { Antitrypsin } \\
\text { (Glycoprotein), reverse }\end{array}$ & 5-TTGAGGGTACGGAGGAGTTCC-3 & 55 \\
\hline $\begin{array}{l}\text { Glucuronosyltransferase 1A, } \\
\text { direct }\end{array}$ & 5-TTGCGAACAACACGATACTT-3 & 55 \\
\hline $\begin{array}{l}\text { Glucuronosyltransferase } 1 \mathrm{~A}, \\
\text { reverse }\end{array}$ & 5-CAAACTCCACCCAGAACACG-3 & 55 \\
\hline $\begin{array}{l}\text { Hepatocyte Nuclear Factor } 4 \\
\text { Alpha, direct }\end{array}$ & 5-GGAACATATGGGAACCAACG-3 & 52 \\
\hline $\begin{array}{l}\text { Hepatocyte Nuclear Factor } 4 \\
\text { Alpha, reverse }\end{array}$ & 5-AACTTCCTGCTTGGTGATGG-3 & 52 \\
\hline Cytochrome P450 3A4, direct & 5-TCACCCTGATGTCCAGCAGAAACT-3 & 58 \\
\hline Cytochrome P450 3A4, reverse & 5-TACTTTGGGTCACGGTGAAGAGCA-3 & 58 \\
\hline
\end{tabular}

Urea concentration was determined by the colorimetric method using Sigma Aldrich kits and standards in the culture medium of the transfected and control MMSC.

Alphafetoprotein determination in culture media was performed using Abbot kits on an AxSym analyzer.

The data obtained were processed by nonparametric statistics. Statistical differences between the groups were established using the Kruskal-Wallis method with further processing by the method of multiple comparisons according to Dunn. The significance of differences compared to baseline was determined using the Wilcoxon test for related samples. 


\section{The results}

Optimization of the protocol for the isolation of MMSC from lipoaspirate.

Classic MMSC extraction technology [18] includes 16 stages, including the processing of tissue with enzymes. The latter is difficult to control due to the fact that the activity of enzymes varies widely from lot to lot, and the composition and amount of connective tissue varies from patient to patient. As a result, the classical technology is labor-intensive (it takes 8-10 hours of continuous operation), and the results of its application are difficult to predict. However, it is known that the greatest amount of MMSC is in the perivascular space [19]. Given this and liposuction technique, one should expect that MMSC will be located in the "salt" part of the lipoaspirate. In the course of a study to optimize the release of MMSC from adipose tissue, the following technology was obtained:

1. Aspirate the "salt" part of the lipoaspirate.

2. Centrifuge at $400 \mathrm{~g}$ for 10 minutes at room temperature

3. Resuspend the pellet in hypotonic PBS for 5 minutes at room temperature

4. Centrifuge at $400 \mathrm{~g}$ for 10 minutes at room temperature

5. Resuspend the pellet in DMEM supplemented with $40 \%$ FBS, 100 units / ml penicillin and 100 units / $\mathrm{ml}$ streptomycin and transfer to vials and place in a $\mathrm{CO} 2$ incubator at $37^{\circ} \mathrm{C}$ and a $\mathrm{CO} 2$ content of $5 \%$

6. A day later, cells and tissue fragments that did not adhere to the surface of the vial were washed three times with standard PBS, replacing the medium with standard (in our case, DMEM / F12 with 10\% FBS, 10 ng / ml FGF, ABAM).

The resulting technology is significantly different from the classical one in the following ways:

1. The end result is well predicted

2. Less labor intensive

3. The duration of the main part of the MMSC allocation process is no more than 1 hour.

4. Not inferior to the classical technology in the number of viable cells obtained with the MMSC phenotype (2 - 4 x 105 cells from $100 \mathrm{ml}$ of lipoaspirate).

\section{Transfection Protocol Optimization}

It is known that the most gentle and effective method of transfection is transfection using liposomes. However, as follows from the protocol of the manufacturer of liposomes, the efficiency of transfection is determined primarily by the ratio of the amounts of DNA and liposomes, as well as the number of liposomes that include DNA based on the number of transfected cells. Also important is the type of cells, the stage of growth of cell culture, passage, and so on. Therefore, in the protocol of any liposome manufacturer, it is strongly recommended that transfection optimization be performed first.

In our study, in relation to MMSC obtained by optimized technology at the 3rd passage and $60-70 \%$ confluency, the optimal conditions for transfection are:

- culture medium - DMEM / F12 with the addition of 10\% FBS,

- the number of transfected cells - 1 x106,

- the amount of plasmid DNA $10 \mathrm{ng}$ in $500 \mu \mathrm{l}$ of deionized water that does not contain enzymes that destroy nucleic acids,

- the amount of liposomes $0.5 \mathrm{ml}$.

After 8 hours of incubation, the medium was replaced with DMEM / F12 medium supplemented with $10 \%$ FBS. Since the puromycin resistance gene is used as the reporter gene in the vector used, puromycin (Sigma) was additionally added to the culture medium at the rate of $5 \mu \mathrm{g} / \mathrm{ml}$ of medium. Under these conditions, cells for which transfection was 
ineffective (the amount of the vector entering the cell nucleus is insufficient or for some reason the vector is inactive) died. Cell viability was assessed by a standard method - vital trypan blue staining, followed by counting in a Fuchs-Rosenthal chamber.

Under these conditions, the transfection efficiency (the number of puromycin-resistant cells in relation to the total number) was $78.2+12.4 \%$.

\section{MMSC Transdifferentiation Evaluation}

6 weeks after transfection, cultured cells acquired morphology similar to the morphology of hepatocytes and accumulated glycogen (Fig. 1).

A study conducted by RT PCR method (table 2) showed that the expression of alphaprotein, usually regarded as a marker of hepatocyte immaturity [20] began to appear in the period 6-12 days after transfection, followed by a decrease, while the expression of the cytokeratin 18 gene, albumin and tryptophan 2,3 dioxygenase was observed from 6 days after transfection and gradually increased over time. In untransfected cells, the expression of alpha-fetoprotein, tyrosin aminotransferase and other proteins synthesized mainly by hepatocytes was not found. The observed dynamics, apparently, describes the process of transdifferentiation of aMMSC into hepatocytes under the influence of ectopic expression of HGF, which is one of the factors determining the growth and development of hepatocytes.

The latter is confirmed by the delayed ( 3 weeks after transfection) expression of the main hepatocyte markers - tyrosinaminotransferase, cytochrome P450 and nuclear factor of hepatocytes, the presence of which is characteristic of adult liver.

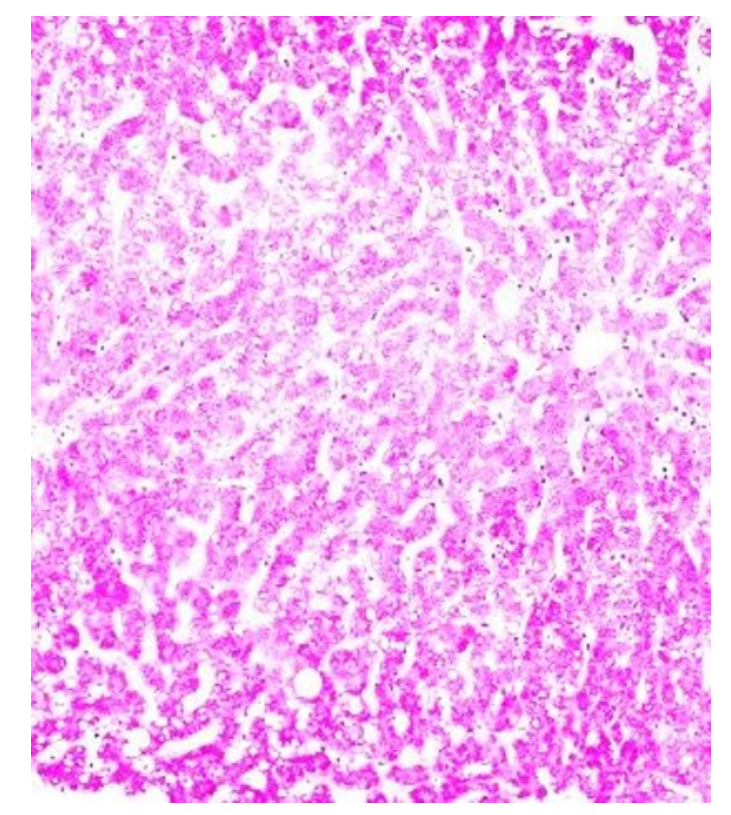

Fig. 1. Schiff stain + hematoxylin / eosin, bright field, 40x.

Between 6 and 21 days, transfected aMMSCs, in contrast to intact ones, demonstrated the ability to produce urea and alpha-fetoprotein (Table 3), although the quantitative characteristics of the synthesis were lower than when culturing mature hepatocytes. 
This observation also fits into the confirmation of the hypothesis about the differentiation of transfected aMSMS into hepatocytes and their gradual maturation.

Table 2. The dynamics of expression of hepatocyte marker genes.

\begin{tabular}{|l|c|c|c|c|}
\hline \multirow{2}{*}{ Hepatocyte marker gene } & \multicolumn{4}{|c|}{ Day after transfection } \\
\cline { 2 - 5 } & 6 & 12 & 21 & 42 \\
\hline Beta actin & $0,32 \pm 0,1$ & $4,12+0,34^{*}$ & $4,59 \pm 0,29^{*}$ & $4,45 \pm 0,28^{*}$ \\
\hline Alpha fetoprotein & $0,68 \pm 0,06$ & $7,88 \pm 0,39^{*}$ & $3,14 \pm 0,55^{*}$ & $2,53 \pm 0,62^{*}$ \\
\hline Cytokeratin 18 & $2,57 \pm 0,21$ & $3,11 \pm 0,42$ & $6,57 \pm 0,46^{*}$ & $9,18 \pm 0,39^{*}$ \\
\hline Albumen & $2,72 \pm 0,07$ & $4,13 \pm 0,33^{*}$ & $5,41 \pm 0,35^{*}$ & $6,22 \pm 0,38^{*}$ \\
\hline Tryptophan 2,3-Dioxigenase & $2,12 \pm 0,09$ & $4,52 \pm 0,36^{*}$ & $5,88 \pm 0,51^{*}$ & $5,42 \pm 0,51^{*}$ \\
\hline Tyrosinaminotransferase & $0,11 \pm 0,03$ & $0,12 \pm 0,08$ & $7,88 \pm 0,54^{*}$ & $9,69 \pm 0,72^{*}$ \\
\hline Alpha 1 Antitrypsin & $1,54 \pm 0,17$ & $2,86 \pm 0,32^{*}$ & $3,89 \pm 0,55^{*}$ & $4,78 \pm 0,64^{*}$ \\
\hline Glucuronisiltransferase 1A & $3,1 \pm 0,13$ & $2,99 \pm 0,25$ & $3,45 \pm 0,62$ & $4,01 \pm 0,4^{*} 7$ \\
\hline $\begin{array}{l}\text { Hepatocyte Nuclear Factor 4 } \\
\text { alpha }\end{array}$ & $0,44 \pm 0,12$ & $2,89 \pm 0,24^{*}$ & $3,46 \pm 0,49^{*}$ & $5,47 \pm 0,42^{*}$ \\
\hline Cytochrome P450 3A4 & $0,13 \pm 0,01$ & $1,01 \pm 0,2^{*}$ & $5,55 \pm 0,41^{*}$ & $6,27 \pm 0,38^{*}$ \\
\hline
\end{tabular}

Note: * - significance of differences from 6 days after transfection $(\mathrm{p}<0.05)$

Table 3. The dynamics of the synthesis of transfected MMSC urea and alpha fetoprotein

\begin{tabular}{|l|c|c|c|}
\hline \multirow{2}{*}{} & \multicolumn{3}{|c|}{ Day after transfection } \\
\cline { 2 - 4 } & 6 & 12 & 21 \\
\hline Urea, pg / cell / hour & $5,23 \pm 0,12$ & $20,01 \pm 0,24 *$ & $25,57 \pm 0,42 *$ \\
\hline $\begin{array}{l}\text { PCG alpha-fetoprotein / } 10^{6} \\
\text { cells / hour }\end{array}$ & $13,62 \pm 0,51$ & $10,56 \pm 0,19$ & $8,14 \pm 0,28^{*}$ \\
\hline
\end{tabular}

Note: * - significance of differences from 6 days after transfection $(\mathrm{p}<0.05)$

Thus, as a result of the work, cells with biochemical and histological signs of hepatocytes were obtained.

The procedure for obtaining hepatocytes from multipotent mesenchymal stromal cells is simple and allows you to fully control the properties of the resulting cells.

The availability of MMSC and their ability to expand in vitro allows the production of hepatocytes for clinical use in the treatment of liver failure.

\section{Conclusion}

In the process of research, optimization of protocols for the isolation of multipotent mesenchymal stromal cells from lipoaspirates and transfection of cells with a plasmid vector including the hepatocyte growth factor gene was performed. This made it possible to obtain cells from multipotent mesenchymal stromal cells from human adipose tissue that exhibit phenotypic signs of hepatocytes.

\section{Reference}

1. J.A. Villarreal, N.L. Sussman, Tex Heart Inst. J., 6(1) (2019)

2. A.R. Çalışkan, M. Harputluoğlu, J. Gastroenterol., 30(10) (2019)

3. F. EBöhm, U.A. Köhler, T. Speicher, S. Werner, EMBO Mol. Med., 2(8), 294-305 doi: 10.1002/emmm.201000085, 
4. P.A. Lysy, D. Campard, F.Smets, M.Najimi, E.M Sokal, Stem cells for liver tissue repair - p. K. Hoffmann, A.J. Nagel, K. Tanabe, J. Fuchs, K. Dehlke, O. Ghamarnejad, A. Lemekhova, A. Mehrabi, BMC Surg, 20(1), 31 doi: 10.1186/s12893-019-0664-8 PMID: 32050952; PMCID: PMC7017496

5. H. Caplan, S.D. Olson, A. Kumar, M. George, K.S. Prabhakara , P. Wenzel, S. Bedi, N. Toledano-Furman, F. Triolo, J. Kamhieh-Milz, G. Moll, C.S. J. Cox, Mesenchymal Stromal Cell Therapeutic Delivery, (2019)

6. Si. Zizhen, Xue Wang, Changhui Sun, Yuchun Kang, Jiakun Xua, Xidi Wang, Yang Hui.. Biomedicine \& Pharmacotherapy, 114, 108765 (2019)

7. M. Alvarez-Dolado, Pardal R. Garcia-Verdugo, Nature, 425, 968 (2003)

8. S.A. Selim, S.A.A., El-Baset, A.A.A. Kattaia, Histochem Cell Biol, 151, 249-262 (2019). G.J. Jimenez-Puerta, J.A. Marchal, E. López-Ruiz, P. Gálvez-Martín, J. Clin. Med., 9(2) https://doi.org/10.3390/jcm9020445

9. S. Kern, H. Eichler, J. Stoeve, Stem Cells , 24, 1294 (2006)

10. B. Onka, S. Aggarwal et al., Hep., 9, 607(2019)

11. H. Edward, H. Sunami, Y. Shimizu, Regenerative Therapy, 14, 136 (2020) G. Vassilopoulos, P.R. Wang, D.W. Russell Nature, 422, 901, (2003)

12. H. Seung, L. Hansang ee, Y. DongGil, V. Nguyen, D. Song, B. Oh, S.Shin, J. Choi, J. Dong Kim, C. Pan, D. Jo, Y. Woo Cho, Ki Choi, J. Hyung Park, Journal of Controlled Release, 320, 328 (2020)

13. R.E. Schwartz, M. Reyes, L. Koodie, Y. Jiang, M. Blackstad, T. Lund, et. al., J. Clin. Invest., 109, 1291 (2002)

14. S.A. Bustin, J. Mol. Endocrinol., 29, 23 (2002)

15. P.A. Zuk, Tissue Eng., 7, 211 (2001)

16. G.K. Michalopoulos, Gene Expr., 11, 75 (2003)

17. A.J. Strain, T. Ismail, H. Tsubouchi, N. Arakaki, W.C. Bowen, J. Clin. Inves., 1991, 87 (2007)

18. M.J. Gómez-Lechón, J. Castelli, I.Guillén, Hepatology, 21, 1248 (1995)

19. S.H. Oh, M. Miyazaki, H. Kouchi, Y. Inoue, M. Sakaguchi, T. Tsuji, Biochem. Biophys. Res. Commun., 279, 2 (2000)

20. L.De Bartolo, S. Morelli, L.C. Lopez, Biomaterials, 26, 4432 (2005) 